\title{
Effect of Nitrogen Source and Concentration on Growth and Activity of Nitrogen Assimilation Enzymes in Roots of a Moroccan Sorghum Ecotype
}

\author{
Reda Ben Mrid, Redouane El Omari, Mohamed Nhiri* \\ Laboratory of Biochemistry and Molecular Genetics, Faculty of Science and Technology, Tangier, Morocco \\ Email address: \\ rbenmrid@gmail.com (R. Ben Mrid), redomari@hotmail.com (R. El Omari), med.nhiri@gmail.com (M. Nhiri) \\ ${ }^{*}$ Corresponding author
}

To cite this article:

Reda Ben Mrid, Redouane El Omari, Mohamed Nhiri. Effect of Nitrogen Source and Concentration on Growth and Activity of Nitrogen Assimilation Enzymes in Roots of a Moroccan Sorghum Ecotype. Plant. Vol. 4, No. 6, 2016, pp. 71-77. doi: 10.11648/j.plant.20160406.14

Received: September 23, 2016; Accepted: October 8, 2016; Published: October 31, 2016

\begin{abstract}
Carbon and nitrogen metabolism pathways are regulated by complex mechanisms in order to optimize growth and development of plants. This study was conducted to contribute to the determination of roles of some key enzymes of carbon and nitrogen metabolism in sorghum roots. Sorghum were grown under nitrate $\left(\mathrm{NO}_{3}{ }^{-}\right)$, ammonium $\left(\mathrm{NH}_{4}{ }^{+}\right)$or nitrate combined to ammonium at different concentrations. Growth parameters and protein content were evaluated. In addition, we analyzed key enzymes activities involved in nitrogen and carbon metabolism such as: nitrate reductase (NR), glutamine synthetase (GS), aspartate aminotransferase (AAT) and phosphoenolpyruvate carboxylase (PEPC). At high nitrogen levels (ammonium or nitrate), the sorghum roots showed an increase in biomass accompanied by an increase in protein content. Likewise, high concentrations induced accumulation of the non-photosynthetic isoform of phosphoenolpyruvate carboxylase. Glutamine synthetase and aspartate aminotransferase activities were also increased, especially at high levels of ammonium. These results showed that sorghum plants have an efficient system for nitrogen assimilation in their roots, allowing this plant to tolerate excessive concentration of this nutrient.
\end{abstract}

Keywords: Sorghum, Nitrogen Stress, Nitrogen Metabolism, Ammonium, Nitrate

\section{Introduction}

Fertilisation is a prerequisite to meet high yields and optimum quality of crops. Unlike most of mineral elements essential to plant development and which are needed in trace amounts, some key elements like nitrogen $(\mathrm{N})$, phosphorus (P) and potassium $(\mathrm{K})$ are needed in large amounts, these elements are frequently in short supply in the soil to allow optimal growth of crops. Of all mineral elements, nitrogen is the one that organisms require in greatest quantity [1], adequate nitrogen fertilization is therefore of importance for better growth.

Nitrate $\left(\mathrm{NO}_{3}{ }^{-} \mathrm{N}\right)$ and ammonium $\left(\mathrm{NH}_{4}{ }^{+}-\mathrm{N}\right)$ are the major forms of nitrogen that plants use for growth and development. These two forms of inorganic nitrogen are absorbed by specific transport systems in roots. $\mathrm{NO}_{3}^{-}-\mathrm{N}$ is converted to $\mathrm{NO}_{2}^{-}-\mathrm{N}$ and then to $\mathrm{NH}_{4}^{+}-\mathrm{N}$ by the sequential action of nitrate reductase (NR) and nitrite reductase (NiR),
Whereas, $\mathrm{NH}_{4}^{+}-\mathrm{N}$ is directly assimilated into amino acids via the concerted activities of glutamine synthetase (GS) and glutamate synthase (GOGAT) [2]. Nitrogen incorporated into glutamine by glutamine synthetase and glutamate by glutamate dehydrogenase can be redistributed to other amino acids, mainly by the action of transaminase or aminotransferase as aspartate aminotransferase (AAT) which catalyzes the reversible transfer of an amino group from glutamate to oxaloacetate to form aspartate and $\alpha$ ketoglutarate.

Carbon skeletons needed for the incorporation of ammonium into amino acids are provided by photosynthesis. Photosynthesis and nitrogen assimilation are two different metabolism pathways but which are tightly linked. Photosynthesis generates NADPH and ATP which are used in the synthesis of carbon and nitrogen assimilates, particularly, amino acids and carbohydrates which are the essential building blocks of growing plants. 
PEPC participates in the primary $\mathrm{CO}_{2}$ fixation by $\mathrm{C}_{4}$ and CAM plants leaves [3, 4]. The enzyme also fulfils essential non-photosynthetic functions particularly the anaplerotic replenishment of tricarboxylic acid cycle intermediates for biosynthetic purposes and nitrogen assimilation [5]. This anaplerotic role makes this enzyme an ideal choice to study interaction between carbon and nitrogen metabolism.

Sorghum bicolor (L.) Monech is ranked the $5^{\text {th }}$ most important cereal crop in the world. In most of the countries it is used primarily as animal feed, but in Africa and India it is used as human food, where it is a staple food for millions of people [6]. Sorghum is also a well established model for molecular and physiological studies in photosynthesis and $\mathrm{C}_{4}$ metabolism [7]. A recent study demonstrate that sorghumsudangrass exhibited enhanced biomass production under high levels of inorganic nitrogen supply as well as increased capacity for nitrogen assimilation in roots [8].

In this study we tried to contribute to the understanding of this interaction between carbon and nitrogen metabolism using a Moroccan sorghum ecotype and focusing on some enzymes activities like PEPC, NR, GS, and AAT.

\section{Materials and Methods}

\subsection{Plant Material and Growth}

Sorghum seeds (sorghum bicolor) were sterilized with 5\% of $\mathrm{NaOCl}$ for 15 minutes and washed thoroughly with sterile water and germinated on filter paper (Whatmann paper) in a petri dish soaked in distilled water for 4 days under dark condition at $26^{\circ} \mathrm{C}$ and planted in a pot filled with the vermiculite, and then grown in a growth chamber. The environmental conditions in the growth chamber were $28^{\circ} \mathrm{C}$ and $16 \mathrm{~h}$ photoperiod. the plants received (twice a week $(100$ $\mathrm{ml} /$ pot)) a nutrient solution of $0.5 \mathrm{mM} \mathrm{KNO}{ }_{3}, 0.375 \mathrm{mM}$ $\mathrm{KH}_{2} \mathrm{PO}_{4}, 0.125 \mathrm{mM} \mathrm{K} \mathrm{HPO}_{4}, 0.375 \mathrm{mM} \mathrm{MgSO} 4,1.25 \mathrm{mM}$ $\mathrm{CaSO}_{4}, 10 \mathrm{mg} / \mathrm{L} \mathrm{Fe}$-ethylene-diamine tetraacetate (EDTA) and micronutrients [9], $\mathrm{pH} 6.2 \pm 0.2$. For the treated cultures, the nutrient solution was supplemented by different concentrations of $\mathrm{KNO}_{3}$ or $\left(\mathrm{NH}_{4}\right)_{2} \mathrm{SO}_{4}$ or both at concentration of 5, 20 and $50 \mathrm{mM}$. Roots were harvested 21 days after the start of nutritional treatment. Roots were quickly and gently washed with deionized water to remove residual vermiculite. All enzyme preparations were performed with freshly harvested plants.

\subsection{Growth Parameters}

After 21 days of Nitrogen treatment, 10 plants from each group were used to measure fresh weights and lengths of roots.

\subsection{Extraction and Assay of PEPC}

Roots were extracted in a prechilled mortar and pestle in an extraction buffer containing $100 \mathrm{mM}$ Hepes-KOH, $\mathrm{pH} \mathrm{8,10} \mathrm{mM} \mathrm{MgCl} 2,1 \mathrm{mM}$ EDTA, $10 \%$ (v/v) glycerol, 14 $\mathrm{mM}$ b-mercaptoethanol, $1 \mathrm{mM}$ phenylmethylsulphonyl fluoride (PMSF) and sand. The homogenates were centrifuged at $15000 \mathrm{~g}$ for $15 \mathrm{~min}$ at $4^{\circ} \mathrm{C}$. Ammonium sulphate was added at $60 \%$ to the supernatant. The solution was centrifuged at $12,000 \mathrm{~g}$ for $15 \mathrm{~min}$ at $4^{\circ} \mathrm{C}$. The pellet containing the PEPC was taken up in the same extraction buffer and used for enzyme assays and protein determination. The PEPC enzymatic activity was spectrophotometrically measured by monitoring NADH oxidation at $340 \mathrm{~nm}$ for $5 \mathrm{~min}$ at $30^{\circ} \mathrm{C}$. The assay medium (1 mL) contained $100 \mathrm{mM}$ Hepes-KOH, pH 7.3, $5 \mathrm{mM}$ $\mathrm{MgCl}_{2}, 5 \mathrm{mM} \mathrm{NaHCO}, 0.2 \mathrm{mM} \mathrm{NADH}, 5 \mathrm{U}$ malic dehydrogenase $(\mathrm{MDH})$ and $100 \mu \mathrm{L}$ of the enzyme solution. The reaction was initiated by adding $1 \mathrm{mM}$ phosphoenolpyruvate and the change in $\mathrm{A}_{340}$ was monitored.

\subsection{Glutamine Synthetase}

Roots were extracted in a cold mortar and pestle with grinding medium containing $50 \mathrm{mM}$ Tris- $\mathrm{HCl} \mathrm{pH} 8.0,5 \mathrm{mM}$ $\mathrm{MgSO}_{2}, 12 \mathrm{mM}$ Glutamate, $2 \mathrm{mM}$ EDTA, $10 \%(\mathrm{v} / \mathrm{v})$ glycerol, $0.1 \%(\mathrm{v} / \mathrm{v})$ 2-mercaptoethanol. The homogenate was centrifuged at $13,000 \mathrm{~g}$ for $30 \mathrm{~min}$ at $4 \mathrm{C}$. Glutamine synthetase activity was measured using the transferase assay as described by Shapiro and Stadtman [10]. The assay mixture consisted of $90 \mathrm{mM}$ imidazole- $\mathrm{HCl}(\mathrm{pH} 7.0), 120$ $\mathrm{mM}$ L-glutamine, $3 \mathrm{mM} \mathrm{MnCl}_{2}, 0.4 \mathrm{mM}$ ADP, $20 \mathrm{mM}$ sodium arsenate, $60 \mathrm{mM} \mathrm{NH} \mathrm{H}_{2} \mathrm{OH}$ and the enzyme solution in a final volume of $2.25 \mathrm{ml}$. The L-glutamine was omitted in the blank test. The reaction was started by adding $\mathrm{NH}_{2} \mathrm{OH}$ (prepared freshly, and neutralized to $\mathrm{pH} 7.0$ with $\mathrm{NaOH}$ ) and incubated at $37^{\circ} \mathrm{C}$. The reaction was stopped by adding 0.75 ml of a mixture $(1: 1: 1)$ of $10 \% \mathrm{FeCl}_{3} \cdot 6 \mathrm{H}_{2} \mathrm{O}$ (in $0.2 \mathrm{~N} \mathrm{HCl}$ ), $24 \% \mathrm{TCA}$ and $5 \% \mathrm{HCl}$ after $15 \mathrm{~min}$. The appearance of $\gamma$ glutamyl hydroxamate was measured at $540 \mathrm{~nm}$.

\subsection{Nitrate Reductase}

Roots were homogenized in chilled mortar and pestle with $100 \mathrm{mM}$ potassium phosphate buffer ( $\mathrm{pH}$ 7.4) containing 7.5 $\mathrm{mM}$ cysteine, $1 \mathrm{mM}$ EDTA, $1 \mathrm{mM}$ PMSF and $1.5 \%(\mathrm{w} / \mathrm{v})$ casein. The homogenate was centrifuged at 20,000g for 20 $\min$ at $4{ }^{\circ} \mathrm{C}$. Ammonium sulphate was added at $60 \%$ to the supernatant. The solution was centrifuged at $20,000 \mathrm{~g}$ for 20 min at $4{ }^{\circ} \mathrm{C}$. The pellet was taken up in 500 ul of $100 \mathrm{mM}$ hepes-KOH $\mathrm{pH}$ 7.55. Nitrate reductase activity (NRA) was determined according to the method described by Kaiser et Lewis [11]. The reaction mixture contained $100 \mathrm{mM}$ Tris$\mathrm{HCl}, \mathrm{pH} 7.55,5 \mathrm{mM} \mathrm{KNO}_{3}, 0.2$ to $0.3 \mathrm{mM} \mathrm{NADH}$. The reaction is initiated by addition of $0.1 \mathrm{ml}$ of the protein extract. As there is, in the extract, endogenous NADH oxidase activity, control is performed without $\mathrm{NO}_{3}{ }^{-}-\mathrm{N}$. After 20 minutes of incubation at $30^{\circ} \mathrm{C}, 1 \mathrm{ml}$ of $1 \%$ sulfanilamide (w / v) were added to this medium. After stirring, $1 \mathrm{ml}$ naphthylethylenediamine dihydrochloride (NED) $0.02 \%$ (w/ v) were added, and the mixture was stirred again. Nitrite formed will then be determined by colorimetry at $540 \mathrm{~nm}$ using a standard curve elaborated with a nitrite solution 0.1 $\mathrm{mg} / \mathrm{ml}$. NR activity was expressed as $\mathrm{nmol} \mathrm{NO}_{2}^{-}-\mathrm{N}$ formed 
per minute and per mg protein.

\subsection{Aspartate Aminotransferase}

Aspartate aminotransferase activity was measured by coupling oxalacetate production with malate dehydrogenase and NADH and measuring the decrease in absorbance at 340 $\mathrm{nm}$ at $30^{\circ} \mathrm{C}$ in a $1 \mathrm{ml}$ assay mixture containing: Tris- $\mathrm{HCl} 50$ $\mathrm{mM}, \mathrm{pH} 7.8$, L-aspartate $50 \mathrm{mM}$, 2-oxoglutarate $10 \mathrm{mM}$, NADH $0.1 \mathrm{mM}, 2 \mathrm{U}$ of $\mathrm{MDH}$ and $20 \mu \mathrm{l}$ of roots extract. The reaction was initiated by adding 2-oxoglutarate.

\subsection{Estimation of Protein}

Protein concentration was estimated by the method of Bradford \& al. [12] using BSA as standard.

\subsection{Non-denaturing PAGE and In-gel PEPC and AAT Activity}

Samples were submitted to nondenaturing polyacrylamide gels $\left(7 \%\right.$ separating gel and $5 \%$ stacking gel) at $4{ }^{\circ} \mathrm{C}(80 \mathrm{~V}$ for 3 hours). After protein migration, the gels were incubated in a reaction medium containing for the PEPC activity, $100 \mathrm{mM}$ Tris- $\mathrm{HCl}, \mathrm{pH} 8,40 \mathrm{mM} \mathrm{NaHCO}_{3}, 30 \mathrm{mM} \mathrm{MgSO}_{4}$ and $0.05 \%$ (w / v) PEP. For the AAT activity, gel was stained by incubation in a solution composed of $100 \mathrm{mM}$ Tris- $\mathrm{HCl}$ buffer $\mathrm{pH} 7.5,40 \mathrm{mM}$ L-aspartate and $5 \mathrm{mM}$ 2-oxoglutaric acid. After $15 \mathrm{~min}$ of incubation, the gels were removed from the medium, rinsed with distilled water and then the band corresponding to the PEPC and AAT were detected by the staining method using $0.3 \%(\mathrm{w} / \mathrm{v})$ Fast Violet B Salt solubilized in $100 \mathrm{mM}$ Tris- $\mathrm{HCl}, \mathrm{pH} 8$.

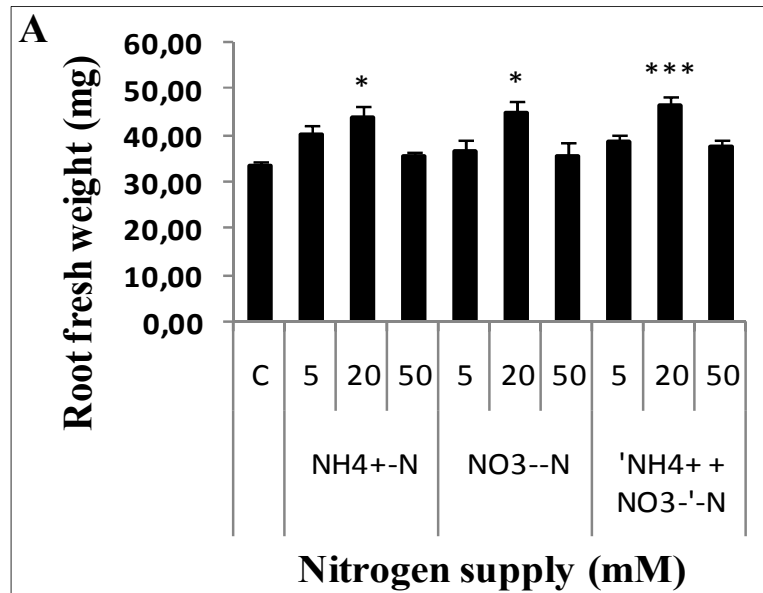

\subsection{Statistical Analysis}

The data shown mean values \pm S.D. Results were subjected to a one-way analysis of variance with a least significant difference (LSD) test between means using PASW Statistics 8.0. Levels of significance were represented by *, ** and *** at $P<0.05, P<0.01$ and at $P<0.001$ respectively.

\section{Results and Discussion}

Several plant species treated with low concentrations of ammonium as sole nitrogen source did not grow as well as when they are supplied with the same concentration of nitrate or ammonium combined to nitrate $[13,14]$. The results presented in Fig. 1 show that the most significant growth was observed in plants treated with $20 \mathrm{mM}$ ammonium or 'ammonium + nitrate'. However, similar biomass production was observed at very high concentration ( $50 \mathrm{mM}$ nitrogen $)$ in leaves (data not shown) and roots compared to plants treated with 0.5 and $5 \mathrm{mM}$ nitrogen. High concentrations of nitrogen has also an effect on protein content (Fig. 2), in fact, $20 \mathrm{mM}$ of ammonium and $50 \mathrm{mM}$ of 'ammonium + nitrate' supply allow a greater accumulation of protein content compared with control plants. One of the most conspicuous characteristics of sorghum is its tolerance to high levels of ammonium. Sorghum tolerance was suggested to be due to the presence of a glutamine synthetase in its roots, involved in ammonium detoxification [8]. The increase in sorghum biomass under nitrogen-rich conditions, particularly under ammonium supply [8], would partly explain our experimental results reported in this study.

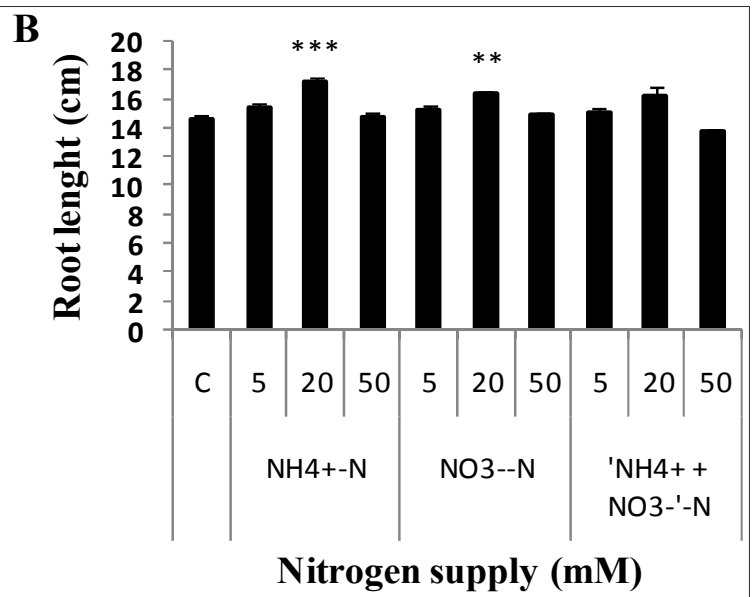

Figure 1. Biomass accumulation of sorghum roots growing at increased levels of inorganic nitrogen supply. Control sample corresponds to plants grown under low nitrogen (nitrate $0.5 \mathrm{mM}$ ). Length $(A)$ and fresh weight (B) values are the mean of 10 or 8 plants per treatment \pm standard error. Means were compared by Tukey's test $(P \leq 0,05)$.

Fig. 3A shows that PEPC activity was induced by high concentrations of nitrogen. Plants supplied with ammonium showed a very significant increase in PEPC activity compared to the control plants especially at $50 \mathrm{mM}$ ammonium. Plants treated with 'ammonium + nitrate' showed an intermediate increase in PEPC activity compared to plants treated with ammonium or nitrate as sole nitrogen source. To determine whether this activity is due to covalent modification of the enzyme by phosphorylation and / or accumulation of polypeptides after nitrogen treatment, proteins from each condition were subjected to nondenaturing polyacrylamide gel electrophoresis (PAGE) followed by in-gel PEPC activity staining. The results obtained in Fig. 3B showed that the intensity of PEPC band 
was greater when plants were treated with ammonium and 'nitrate + ammonium' compared to plants supplied with nitrate as sole nitrogen source. These results are consistent with the work reported by Lasa \& al., [15] who showed that PEPC activity in pea roots is three times greater in plants treated with ammonium compared to nitrate [15]. Other authors have assessed the action of ammonium in stimulating root PEPC activity [16, 17 and 18]. Viktor and Cramer [19] argued that tomato cultivar F144 showed higher PEPC activity under ammonium nutrition. It has been also shown, in several studies, an accumulation of amino acids mainly in roots of nitrogen-fed plants and particularly in ammoniumfed plants [18, 20 and 21]. The accumulation of amino acids in the roots suggested that much of the ammonium ion is not substantially transported into the xylem sap and is mainly assimilated in the roots [22], thereby requiring a sufficient supply of keto acids, especially 2-oxoglutarate and oxaloacetate for the synthesis of glutamic acid and aspartic acid and their amides; glutamine and asparagine. Thus, the increase in PEPC activity in roots could be essential for the supply of carbon compound required for the synthesis of these amino acids (Fig. 3).

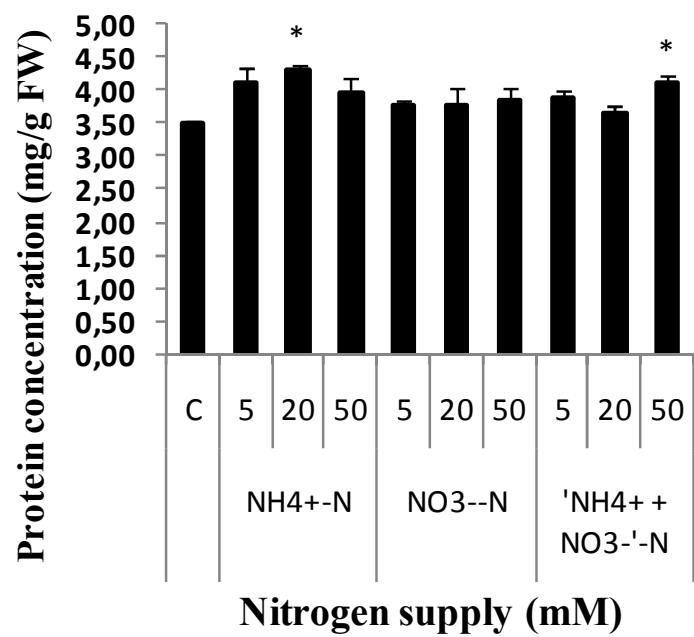

Figure 2. Protein content of sorghum roots. Plants were treated with different nitrogen sources (ammonium, nitrate or 'ammonium + nitrate'). Control sample corresponds to plants grown under low nitrogen (nitrate 0.5 $m M)$. Proteins were assayed according to the Bradford method at $595 \mathrm{~nm}$ and expressed as $\mathrm{mg} / \mathrm{g}$ fresh weight. Values represent the means \pm standard error of $n=3$ independent experiments. Means were compared by Tukey's test $(P \leq 0,05)$.

Results reported in Fig. 4 illustrate the nitrate reductase activity in roots of plants treated with different sources and concentrations of nitrogen. Nitrate as sole nitrogen source induce an increase in the NR activity, mainly at 20 and 50 $\mathrm{mM}$ nitrate. This activity is slightly induced by 'nitrate + ammonium' supply. Our results are in agreement with the results obtained by El Omari et al., and Robin et al., [21, 23], who found a clear relationship between the concentration of nitrate and nitrate reductase activity in sorghum roots. Atkins et al., [24] and Fan et al., [25] reported that NR activity of Phaseolus vulgaris roots and five legumes roots increased linearly with the increasing concentration of nitrate. There was no significant increase in NR activity in sorghum roots of ammonium treated plants (Fig. 4). This activity was slightly lower at $20 \mathrm{mM}$ ammonium compared to the control plants. Munzarova et al., [26] found that nitrate reductase activity was low in Phragmites australis and Glyceria maxima roots treated with only ammonium. Oaks et al., [27] reported a decrease in NR activity of maize roots in the presence of ammonium as nitrogen source at $\mathrm{pH} 7.5$, however, the NR activity is stimulated at $\mathrm{pH}$ 5.8. Therefore, $\mathrm{pH}$ of the culture medium is an important factor determining the effect of ammonium on NR activity. In our experimental conditions, $\mathrm{pH}$ of the culture medium was $6.2 \pm 0.2$. From these results it could be assumed that the increase in NR activity observed in plants treated with 'nitrate + ammonium' would be due to the proportion of the nitrate (Fig. 4).

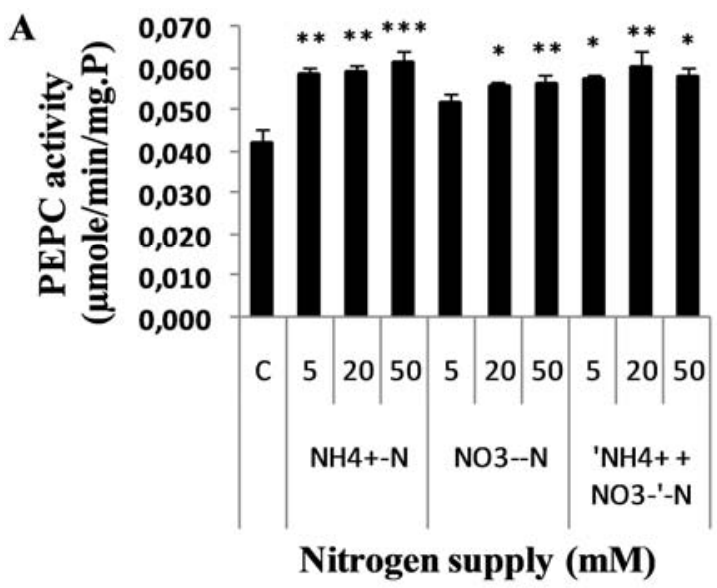

B

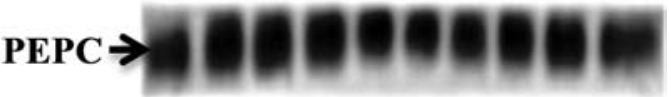

Figure 3. PEPC activity of sorghum roots treated with different nitrogen sources (ammonium, nitrate or 'ammonium + nitrate'). A; enzymatic activity in solution. Values represent the means \pm standard error of $n=3$ independent experiments. Means were compared by Tukey's test $(P \leq 0,05)$. B; in gel $P E P C$ activity, $25 \mu \mathrm{g}$ of roots protein were used for each sample. Control sample corresponds to plants grown under low nitrogen (nitrate $0.5 \mathrm{mM}$ ).

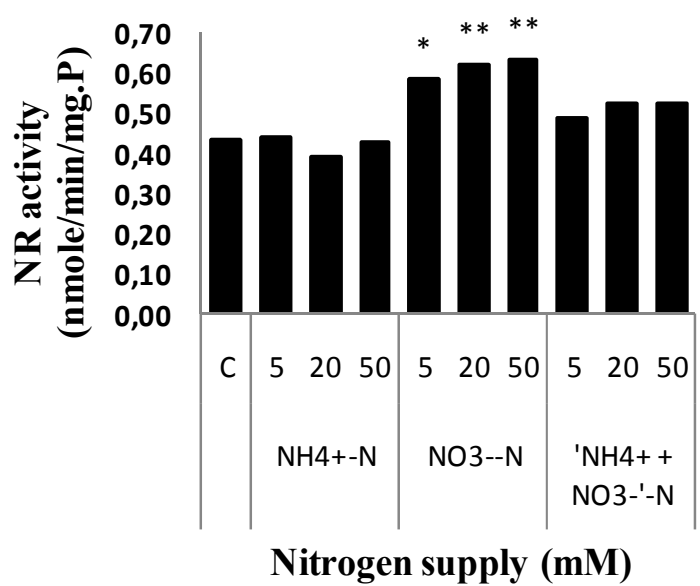

Figure 4. Nitrate reductase activity (NR) in sorghum roots treated with different nitrogen sources. Values represent the means \pm standard error of $n=3$ independent experiments. Means were compared by Tukey's test ( $P \leq$ $0,05)$. Control sample corresponds to plants grown under low nitrogen (nitrate $0.5 \mathrm{mM}$ ). 


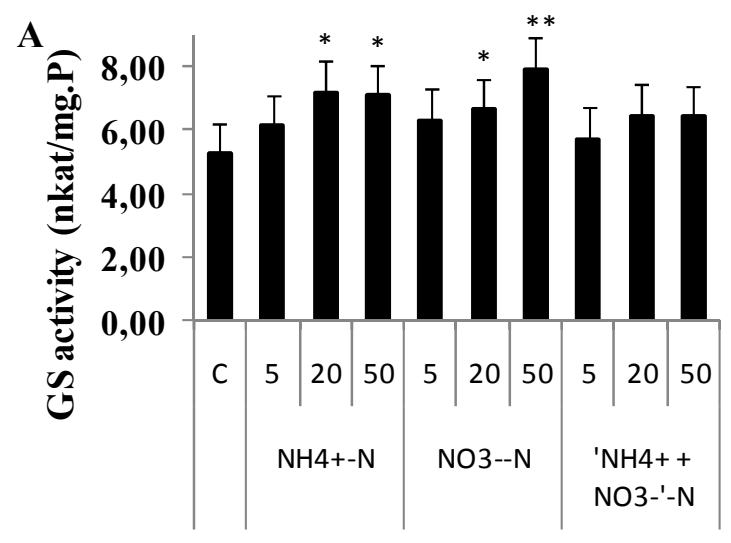

Nitrogen supply (mM)

Figure 5. GS activity at increasing concentrations of different sources of nitrogen (ammonium, nitrate or 'ammonium + nitrate'). Values represent the means \pm standard error of $n=3$ independent experiments, and samples treated by nitrate or ammonium. Control sample corresponds to plants grown under low nitrogen (nitrate $0.5 \mathrm{mM}$ ).

Results showed in Fig. 5 indicate that, regardless of the nitrogen source (ammonium or nitrate), there was a significant increase in glutamine synthetase activity in sorghum roots at 20 and $50 \mathrm{mM}$ concentration. This increase was the same for all the three sources of nitrogen at $5 \mathrm{mM}$ concentration. However, the highest activity was observed in plants treated with $50 \mathrm{mM}$ nitrate. The nitrogen source (ammonium + nitrate) has a lower activity compared to nitrate or ammonium used as sole nitrogen source. The increase in GS activity in the presence of ammonium was already reported in a study on soybean nodules and roots $[8$, 28]. Sugiyama and Sugiharto [20] showed that ammonium increased the GS and Fd-GOGAT activities, while nitrate leads to a relative increase of Fd-GOGAT activity compared to GS activity. The increase in GS activity on medium containing large amounts of ammonium is necessary for assimilation of this toxic compound. The reduction of nitrate to ammonium in the roots could be an explanation for the induction of GS activity in the presence of nitrate. As we noted in the introduction part, high concentration ammonium is toxic to many species of plants. In the light of a previous work [8], our present data confirm sorghum tolerance to large amounts of ammonium. This tolerance might be the result of a root GS activity that will support the excess of ammonium since its uptake by the root and its conversion into organic acids, which would save the sheet of ammonia syndrome [8]. The GS in this direction allow detoxification of the plant in soils containing high amounts of ammonium.

Until recently, it was thought that the aspartate was synthesized in plants by the action of an aspartate aminotransferase (AAT) similar to AAT existing in mammals; but it has recently been discovered a novel enzyme in plants, very similar to the enzyme from cyanobacterium (p-AAT), which has a high affinity for the glutamate [29]. These authors suggested that the physiological role of this AAT resides in the conversion of glutamate to aspartate for the biosynthesis of essential amino acids. In this study, we showed that the concentration of 5
$\mathrm{mM}$ ammonium induced a remarkable increase in aspartate aminotransferase activity (Fig. 6A). Nitrate induced a small increase in AAT activity, 20 and $50 \mathrm{mM}$ nitrogen lead to a lower activity compared to the $5 \mathrm{mM}$ concentration. Indeed, most plants use nitrogen concentrations at the range of 5 to $10 \mathrm{mM}$, therefore, in our conditions; nitrogen excess inhibits the AAT activity. In fact, this enzyme generates glutamate, which is sought by the GS/GOGAT cycle for the consumption of ammonium to yield glutamine. Glutamine is used for the synthesis of amino acids through the transamination reaction of the $\alpha$-ketogularic acid which is a cosubstrate of AAT. According to this hypothesis we suggest that the depletion of substrate and product of AAT was the cause of the decrease in root AAT activity. Aspartate aminotransferase activity gel assay (Fig. 6B), reveals the presence of two isoforms (AAT1 and AAT2). The figure shows that isoform 1 is more abundant than isoform 2, contrary to what we obtained with sorghum leaves, where the isoform 2 were more abundant than isoform 1 (results not shown). In plants, there are various isoenzymes of aspartate aminotransferase localized in different tissues and cell organelles such as cytosol, mitochondria, chloroplasts, peroxisomes and glyoxysomes [30,31]. This suggests that these different forms play different roles in the plant metabolism according to their cellular location. It is also important to note that these isoenzymes respond differently to environmental conditions such as light and nitrogen deficiency [32].

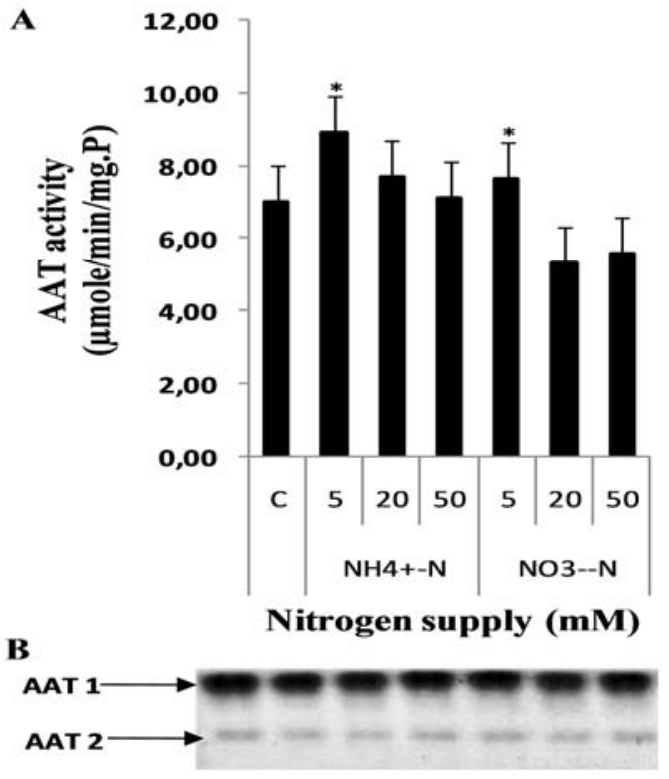

Figure 6. A; AAT activity at increasing concentrations of nitrate or ammonium. Values represent the means \pm standard error of $n=3$ independent experiments. Means were compared by Tukey's test $(P \leq 0,05)$. B; in gel AAT activity, $30 \mu \mathrm{g}$ of roots protein were used for each sample. Control sample corresponds to plants grown under low nitrogen (nitrate $0.5 \mathrm{mM}$ ).

\section{Conclusion}

Our results showed that growth parameters, proteins levels and activities of enzymes involved in nitrogen and carbon 
metabolisms such as; glutamine synthetase, aspartate aminotransferase and phosphoenolpyruvate carboxylase were higher in roots of sorghum plants especially at high levels of ammonium. These results showed that sorghum have an efficient system for nitrogen assimilation in their roots, allowing this plant to tolerate excessive concentration of this nutrient.

\section{References}

[1] Epstein, E., Bloom, A. J., (2005): Mineral Nutrition of Plants: Principles and Perspectives, $2^{\text {nd }}$ edition. Sinauer, Sunderland, MA.

[2] Valadier M. H., A. Yoshida, O. Grandjean, H. Morin, J. Kronenberger, S. Boutet, A. Raballand, T. Hase, T. Yoneyama and A. Suzuki, (2008): Implication of the glutamine synthetase/glutamate synthase pathway in conditioning the amino acid metabolism in bundle sheath and mesophyll cells of maize leaves. F. E. B. S. Journal, 275: 3193-3206.

[3] Nimmo H. G. (2003): Control of the phosphorylation of phosphoenolpyruvate carboxylase in higher plants, Archives of Biochemistry and Biophysics, 414: 189-196.

[4] Izui K., Matsumura H., Furumoto T., Kai Y. (2004): phosphoenolpyruvate carboxylase: a new era of structural biology. Annual Review of Plant Biology, 55: 69-84.

[5] O'Leary B., Park J. and Plaxton W. C. (2011): The remarkable diversity of plant PEPC (phosphoenolpyruvate carboxylase): recent insights into the physiological functions and posttranslational controls of non-photosynthetic PEPCs. Biochemical Journal, 436: 15-34.

[6] Agrama, H. A. and M. R. Tuinstra. (2003): Phylogenetic diversity and relationships among sorghum accessions using SSRs and RAPDs. African. J. Biotechnol., 2 (10): 334-340.

[7] Nhiri M., Bakrim N., Pacquit V., Hachimi-Messouak ZE., Osuna L., Vidal J., (1998): Calcium-dependent and independent phosphoenolpyruvate carboxylase kinases in sorghum leaves: further evidence for the involvment of the calcium-independent protein kinase in the in-situ regulatory phosphorylation of $\mathrm{C}_{4}$ phosphoenolpyruvate carboxylase. Plant Cell Physiol., 39: 241-6.

[8] El Omari R., Rueda-López M., Avila C., Crespillo R., Nhiri N. and M. Cánovas F., (2010): Ammonium tolerance and the regulation of two cytosolic glutamine synthetases in the roots of sorghum. Functional Plant Biology, 37: 55-63.

[9] Arnon D. I. (1938): Microelements in culture solution experiments with higher plants. American Journal of Botany, 25: $322-325$.

[10] Shapiro B. M. and Stadtman E. R. (1970): Glutamine synthetase (Escherichia coli). In H. Tabor and W. C. Tabor (eds.), Methods in Enzymology, Academic Press, New York and London Vol: 17A 910-912.

[11] Kaiser J. J, O. A. H Lewis, (1984): Nitrate reductase and glutamine synthetase activity in leaves and roots of nitrate-fed Helianthus annuus L. Plant and Soil. 70: 127-30.

[12] Bradford M. M. (1976): A rapid and sensitive method for the quantification of microgram quantities of protein utilizing the principle of protein-dye binding. Anal Biochem., 72: 248-254.
[13] Mahmood, T., Kaiser, W. M., (2003): Growth and solute composition of the salt-tolerant kallar grass [Leptochloa fusca, (L.) Kunth] as affected by nitrogen source. Plant and Soil, 252: $359-366$.

[14] Abbasi M. K., Tahir M. M., Rahim N., (2013): Effect of N fertilizer source and timing on yield and $\mathrm{N}$ use efficiency of rainfed maize (Zea mays L.) in Kashmir-Pakistan Geoderma Volumes 195-196, Pages 87-93.

[15] Lasa BS, Frechilla PM, Aparicio-Tejo C, Lamsfus (2002): Role of glutamate dehydrogenase and phosphoenolpyruvate carboxylase activity in ammonium nutrition tolerance in roots, Plant Physiol. Biochem., 40: 969-976.

[16] Arnozis P. A., Nelemans J. A. \& Findenegg G. R. (1988): Phosphoenolpyruvate carboxylase activity in plants grown with eitherNO ${ }_{3}^{-}$or $\mathrm{NH}_{4}{ }^{+}$as inorganic nitrogen source. Journal of Plant Physiology, 132: 23-27.

[17] Viktor A., Cramer M. D. (2005): The influence of root assimilated inorganic carbon on nitrogen acquisition/assimilation and carbon partitioning. New Phytol, 165: 157-69.

[18] Setién I, Vega-Mas I, Celestino N, Calleja-Cervantes M. E., González-Murua C., Estavillo J. M., González-Moro M. B., (2014): Root phosphoenolpyruvate carboxylase and NAD-malic enzymes activity increase the ammonium-assimilating capacity in tomato. Journal of Plant Physiology, 171, Issue 5, 1: 49-63.

[19] Viktor, A and Cramer M. D. (2005): The influence of root assimilated inorganic carbon on nitrogen acquisition/assimilation and carbon partitioning. New Phytol., 165: $157-169$.

[20] Sugiharto, B., and Sugiyama, T. (1992): Effects of nitrate and ammonium on gene expression of phosphoénolpyruvate carboxylase and nitrogen metabolism in maize leaf tissue during recorvery from nitrogen stress. Plant Physiol., 98: 14031408 .

[21] El Omari R., Nhiri M. (2015): Effect of High Levels of Ammonium or Nitrate on Growth and Nitrogen Metabolism in Roots and Leaves of Sorghum (Sorghum sudangrass) Plants. American-Eurasian J. Agric. \& Environ. Sci., 15: 1860-1867.

[22] Britto, D. T., and H. J. Kronzucker. (2005): Nitrogen acquisition, PEP carboxylase, and cellular $\mathrm{pH}$ homeostasis: new views on old paradigms. Plant, Cell and Environment 28: $1396-1409$.

[23] Robin P, D Blayac, L Salsac (1979): Influence of nitric alimentation on nitrite content and nitrate reductase activity of maize roots and leaves. Physiol Veg., 17: 55-66. (French).

[24] Atkins CA, Pate JS, Griftiths GJ. White ST. (1980): Economy or carbon and nitrogen in nodulated and nonnodulated $\left(\mathrm{NO}_{3}{ }^{-}\right.$ grown) cowpea (Vigna unguiculata (L.) Walp). Plant Physiology, 66: 978-983.

[25] Fan X. H., Tang C., \& Rengel Z. (2002): Nitrate uptake, nitrate reductase distribution and their relation to proton release in five nodulated grain legumes. Annals of botany, 90: 315-323.

[26] Munzarova E., Lorenzen B., Brix H., Vojtiskova L., \& Votrubova O. (2006): Effect of NH 4+/NO 3- availability on nitrate reductase activity and nitrogen accumulation in wetland helophytes Phragmites australis and Glyceria maxima. Environmental and Experimental Botany, 55: 49-60. 
[27] Oaks A., Aslam M., Boesel I., (1977): Ammonium and amino acids as regulators of nitrate reductase in corn roots. Plant Physiol., 59: 391-394.

[28] Hirel B, Bouet C, King B, Layzell D, Jacobs F, Verma DPS (1987): Glutamine synthetase genes are regulated by ammonia provided externally or symbiotic nitrogen fixation. EMBO J., 6: $1167-1171$.

[29] De la Torre F. De Santis. Suarez MF. Crespillo R. Canovas FM. (2006): Identification and functional analysis of a prokaryotic-type aspartate aminotransférase: implications for plant amino acid metabolism. Plant J., 46: 414-425.
[30] Wilkie S. E. and Warren M. J. (1998): Recombinant expression, purification, and characterization of three isoenzymes of aspartate aminotranferase from Arabidopsis thaliana. Protein Expr. Purif., 12: 381-389.

[31] Coruzzi G. M. (2003) Primary N-assimilation into amino acids in Arabidopsis. In The Arabidopsis Book (Somerville, C. R. and Meyerowitz, E. M., eds). Rockville, MD: American Society of Plant Biologists, pp. 1-17.

[32] Wadsworth, G. J. (1997): The plant aspartate aminotransferase gene family. Physiol. Plantarum, 100: 998-1006. 